\title{
Assessing Knowledge and Practice Regarding the Management of Dysmenorrhea Among Students at University of Namibia Rundu Campus
}

\author{
Tonata Dengeingei ${ }^{1}$, Laura Uusiku ${ }^{1}$, Olivia N Tuhadeleni ${ }^{2} \&$ Alice Lifalaza ${ }^{2}$ \\ ${ }^{1}$ Department of Midwifery Science, School of Nursing, Faculty of Health Sciences, University of Namibia \\ (UNAM), Rundu campus, Namibia \\ ${ }^{2}$ Department of Community Health Nursing Science, School of Nursing, Faculty of Health Sciences, University of \\ Namibia (UNAM), Rundu campus, Namibia \\ Correspondence: Laura Uusiku, School of Nursing, Faculty of Health Sciences, University of Namibia (UNAM), \\ PO Box 2653, Eliander Mwatale Street, Oshakati, Namibia. Tel: 65-223-2261. E-mail: luuisku@unam.na.
}

Received: May 7, 2020 Accepted: July 8, 2020 Online Published: July 13, 2020

doi:10.5539/gjhs.v12n9p105 URL: https://doi.org/10.5539/gjhs.v12n9p105

\begin{abstract}
Background: Dysmenorrhea is a common gynaecological condition that affects the daily activities of the women who suffer from it. In the education context, female students often have to spend long hours at clinics or doctors' appointments due to dysmenorrhoea, thus having to miss lectures when dysmenorrhea impacts adversely on their studies and academic performance. Purpose: This study sought to determine the knowledge and practice of female students at the University of Namibia, Rundu campus regarding the management of dysmenorrhea
\end{abstract}

Methodology: A quantitative study was employed using a non-experimental, cross-sectional approach. The non-probability sampling method was used with convenient sampling being employed. A total of 303 fulltime female students from the University of Namibia, Rundu Campus were selected to participate in the study. Of the 303 students selected 295 completed the open-ended questionnaires which they were given. The data from the questionnaires was analysed manually and the findings presented in the form of tables, graphs and pie charts.

Results: The study found that dysmenorrhea was affecting $88.1 \%$ of the students at the University of Namibia, Rundu Campus. In addition, there was evidently a lack of knowledge on the management of dysmenorrhea, as $46 \%$ only of the participants appeared to possess adequate knowledge on the management of dysmenorrhea. The study also found that approximately $54.2 \%$ of the participants sought medical assistance when experiencing dysmenorrhea, $30.8 \%$ used home remedies of which $91.3 \%$ were effective, $12.3 \%$ used traditional herbs of which $90.6 \%$ were effective, while $25.3 \%$ exercised or did other activities in order to relieve pain.

Conclusion: The findings indicated that dysmenorrhea was affecting the majority of female students on Rundu Campus although only a few of them possessed adequate knowledge on the management of dysmenorrhea and only about half (46\%) of the respondents sought medical help. Recommendation: The findings indicated the need for the university to build a clinic on campus and to organise student wellness programmes which included the management of dysmenorrhoea.

Keywords: knowledge, practice regarding, management of dysmenorrhea, students, Namibia

\section{Introduction}

During the transition from childhood to adulthood, women experience physical, endocrinal, emotional and mental changes. The onset of menarche is one such change in most women of child-bearing age of 15 to 45 although it may occur earlier or later, depending on an individual. Although menstruation is normal occurrence in a woman's life, severe menstruation pain is not normal as it may impact negatively on daily activities, for example, absence from lectures, failure to do chores, unable to study/concentrate and many others (Calis, 2016).

Dysmenorrhea is a common gynaecological condition which is commonly known as painful menstruation (Kural et al., 2015). Dysmenorrhea is divided into two categories, namely, primary and secondary dysmenorrhea. Primary dysmenorrhea refers to painful menstruation without any pelvic pathology and is the most common form (Yang et al., 2015). The symptoms of primary dysmenorrhea result from the excessive production of prostaglandins and 
their metabolites. In secondary dysmenorrhea, pelvic pathology, such as endometriosis, tumours or pelvic inflammatory disease (PID), contribute to the symptoms (Yang et al., 2015).

The signs and symptoms of dysmenorrhea include cramps in the supra-pubic bone and severe back or thigh pain which are accompanied by nausea and vomiting, diarrhoea, headaches, general discomfort and pain (Chen et al., 2016). In addition, dysmenorrhea has psychological effects which include mood swings, emotional disturbance, anger and other symptoms during menstruation (Gebeyehu et al., 2017). These may begin either before or as menstrual bleeding begin and gradually diminish over one to three days. The pain occurs intermittently and ranges from mild to disabling. According to Derseh et al. (2017), ten out of every one hundred women experience severe pain during menstruation which renders them unable to carry out their daily activities on onset. Moderate to severe dysmenorrhea is more common in women under the age of twenty, particularly students. Several women experience milder menstruation pain after the birth of their first child as compared to before. Approximately $80 \%$ of women suffer from menstruation pain symptoms (MPS) and 50\% seek medical advice (Sinha, Srivastava, Sachan, \& Singh, 2016).

However, it is difficult to determine the prevalence of dysmenorrhea because of the different definitions of the condition. It has been revealed that $84.21 \%$ of college girls in India reported experiencing dysmenorrhea in (Kural et al., 2015), while in Ethiopia, 66.81\% of female students reported that they were suffering from primary dysmenorrhea, with $17.26 \%$ reporting severe pain, $41.19 \%$ reporting moderate pain and $41.63 \%$ reporting mild pain (Derseh et al., 2017). Sinha et al. (2016) indicated that the overall prevalence of dysmenorrhea in the world is $73.9 \%$.

Dysmenorrhea is a serious health problem which also affects adolescents and young people in school, having a significant impact on their daily activities and quality of life. Studies highlight the need for educating adolescent girls on the appropriate and effective management of dysmenorrhea to assist them (Akinnubi et al., 2016). In addition, some students do not seek medical attention despite suffering the consequences as some cultures believe menstruation pain is normal. This assertion is supported by a study conducted by Gebeyehu et al. (2017) on the prevalence, impact and management practice of dysmenorrhea among university students of Gondar in Ethiopia. The study revealed that $16.2 \%$ only of the participants consulted health professionals about their menstrual pain, while more than half $(53.7 \%$ ) of them endured the pain and $36.5 \%$ only of them used medication However, there is no literature and neither are there any statistics on the prevalence of dysmenorrhea in Namibia. Accordingly, the researcher decided to carry out this study to assess the knowledge and practice regarding the management of dysmenorrhea among students at the University of Namibia, Rundu Campus and which may be affecting their studies and daily activities.

\subsection{Goals and Objectives}

The purpose of the study was to determine the knowledge and practice of students at the University of Namibia, Rundu campus regarding the management of dysmenorrhea.

The research objectives included the following:

- To assess the knowledge of students about the management of dysmenorrhea

- To describe the practice of students in respect of the management of dysmenorrhea

- To recommend appropriate practice to the university management on how to assist students to manage dysmenorrhea.

\subsection{Significance of the Study}

It was hoped that the study would help the participants to share their knowledge and, thus, assist students to develop more confidence in the management of dysmenorrhea while also enriching their minds and enlightening them about the difference between the factual truths and taboos about the management of dysmenorrhea. The results of the study may be used to enrich and also to contribute to the knowledge and practice of students, nurses and other health workers in the university regarding the management of dysmenorrhea. It should help to develop theory and contribute to the existing literature on dysmenorrhea in Namibia, as there have been limited studies done on dysmenorrhea in the country. The study may also help in formulating a guideline that may be used during treatment or providing health education to adolescents and young women regarding management of dysmenorrhea Finally, it will also contribute to the validation of existing literature on the management of menstruation pain and could be used by future researchers. 


\section{Research Methodology and Design}

\subsection{Research Design}

The research design of a study refers to the overall plan for gathering the requisite data in research studies (Gray, 2014). The research design for this study was a non-experimental, cross-sectional design. This design guided the researcher to determine the existing knowledge and describe the practice of the students on the management of dysmenorrhea. The study employed a quantitative approach.

\subsection{Population}

According to Kumar (2015), in the research context the population comprises the entire group of persons or objects that are of interest to the researcher, in other words, that meeting the criteria relating to the research topic. The research population for this study was all the fulltime, female students who, at the time of the study, were at the University of Namibia, Rundu campus [N = 1249] from all the faculties. Thus, all female students, whatever their cultural and ethnic groups, and from all the faculties and departments had an equal chance for convenient sampling to participate in the study. In addition, it must be noted that the study population included the female students who were available during the data collection period.

\subsection{Sample}

In the research context a sample is a part or fraction of a whole or a subset of a large set, selected by the researcher to participate in a research study (Brink et al., 2015). The same author stated further that a sample consists of a selected group of the elements or unit of analysis of interest from a defined population. In this study 303 female students from all the faculties made up the sample size.

\subsection{Sampling Methods}

Sampling refers to the process used by the researcher to select a sample from the population in a such way that the sample represents the population of interest (Welma et al., 2015). The study used a non-probability sampling method which involved the convenient sampling technique. According to Brink et al. (2015), the convenient sampling technique is also referred to as 'accidental' or 'availability sampling' and involves the choice of readily available participants of the study. Thus, female students who were willing and available took part in the study.

\subsection{Research Instruments}

Research instruments (research tools) are devices which are used to collect the requisite data in research studies (Brink et al., 2015). This study used a questionnaire as the data collection method with a self-structured questionnaire being used as the tool with which to collect the data. The questionnaire consisted of demographic data as well as open-ended and close-ended questions on the knowledge and practice of students in relation to the way in which they managed dysmenorrhea.

\subsection{Data Collection Procedure}

The researcher sought the approval of the University of Namibia Research Committee and the Director of Rundu campus management before the data collection commenced. The participants were provided with adequate and clear information on the aim and objectives of the study, their rights and what would be required of them. In addition, they were also given informed consent forms to sign. During the data collection each participant was given a close-ended questionnaire complete to enable the researcher to gain an insight into their knowledge and practice regarding management of dysmenorrhea. The data was collected by the researcher at the University of Namibia, Rundu Campus during September and October 2018.

\subsection{Data Analysis}

The data was analysed using the descriptive statistical method (Welman et al.,2015). Descriptive statistics describe and summarise the data which has been collected. The data from the questionnaires was analysed using manual data analysis with descriptive data analysis, such as frequencies and means, being used to analyse the data. The findings were presented in the form of tables, charts and graphs using nominal data as the level of measurement.

\subsection{Ethical Considerations}

Ethical approval to conduct the study was obtained from the Chairperson of the School of Nursing Research Committee, Faculty of Health Sciences at the University of Namibia. The personal consent of the selected participants to take part in the study was obtained after the purpose and significance of the study had been explained to them. Participation in the study was voluntary and the participants were free to withdraw from the study at any time if they so wished. In addition, confidentiality was ensured as the questionnaires handed to the participants were designated by a numerical code instead of their names. These codes were then used in the 
dissertation.

\section{Results}

\section{Section A: Demographic Data}

\subsection{Characteristic of Sample}

A sample size of 303 fulltime female students from first to fourth year from all the faculties on the campus was recruited in the study. However, only 295 responded while eight did not return the questionnaires. The demographic data consisted of the following variables: age group, religion, marital status, gravidity and parity of the respondents.

\subsubsection{Age Groups}

The respondents were between 16 and 49 years of age. They were categorised into age groups and grouped to determine the age group of respondents and the age group the most severely affected by dysmenorrhea. The majority of the participants (47.8\%) were in the age group 22-29 and were found to be the most severely affected by dysmenorrhea as compared to the other age groups, $42 \%$ were in the age group $16-21,9.5 \%$ were in the age group 30-39 and $0.7 \%$ were in the age group 40-49. The last group was the least affected by dysmenorrhea.

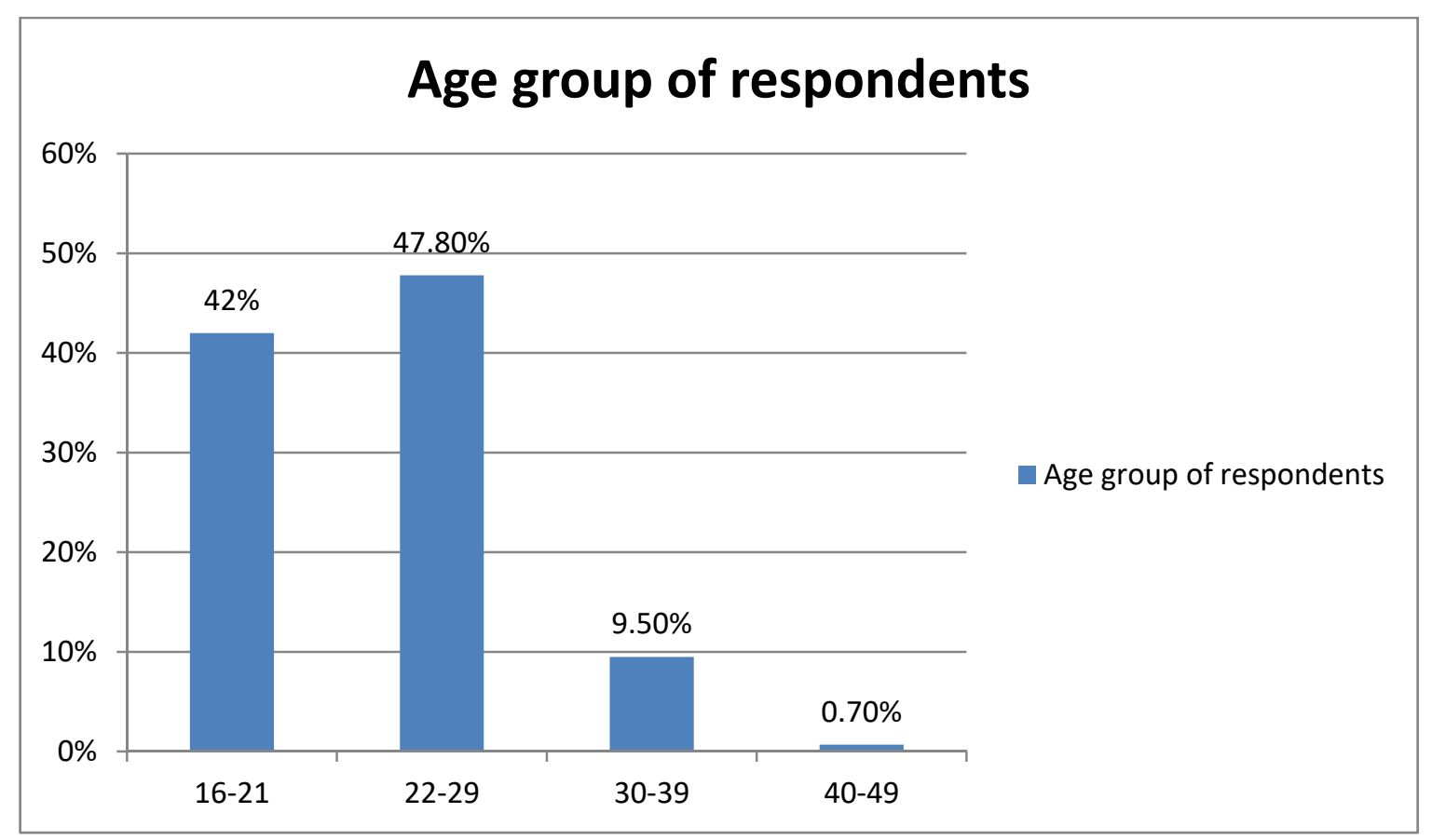

Figure 1. Age of respondents in percentages $(\mathrm{N}=295)$

\subsubsection{Religion}

The respondents were asked to indicate their religion. Of the respondents, $94.6 \%$ indicated they were Christians, $2 \%$ were Jehovah's Witness and 3.4\% were from other religions. There were no Muslin respondents. 


\section{Religion of respondents}

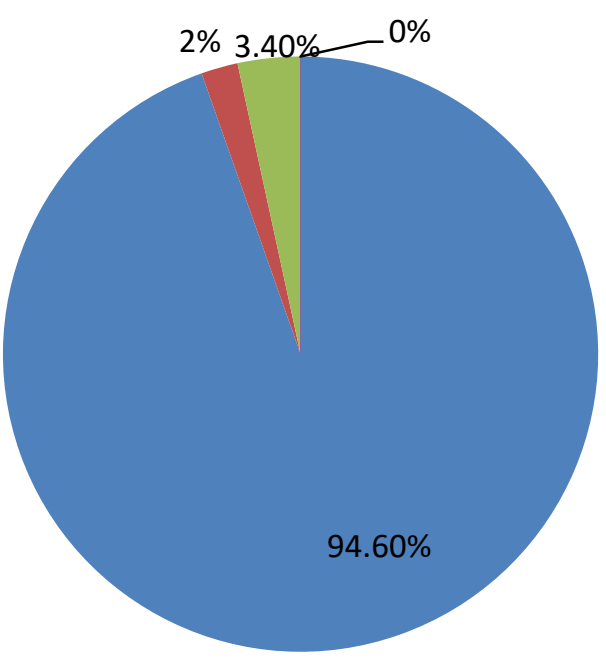

Christian

Jehovah`s Witness

Other religions

Muslim

Figure 2. Religion of participants in percentages $(\mathrm{N}=295)$

\subsubsection{Marital Status}

The respondents were asked to indicate their marital status. Of 295 respondents the majority (98\%) was single and the minority $(2 \%)$ was married. There were no respondents who had been either widowed or divorced.

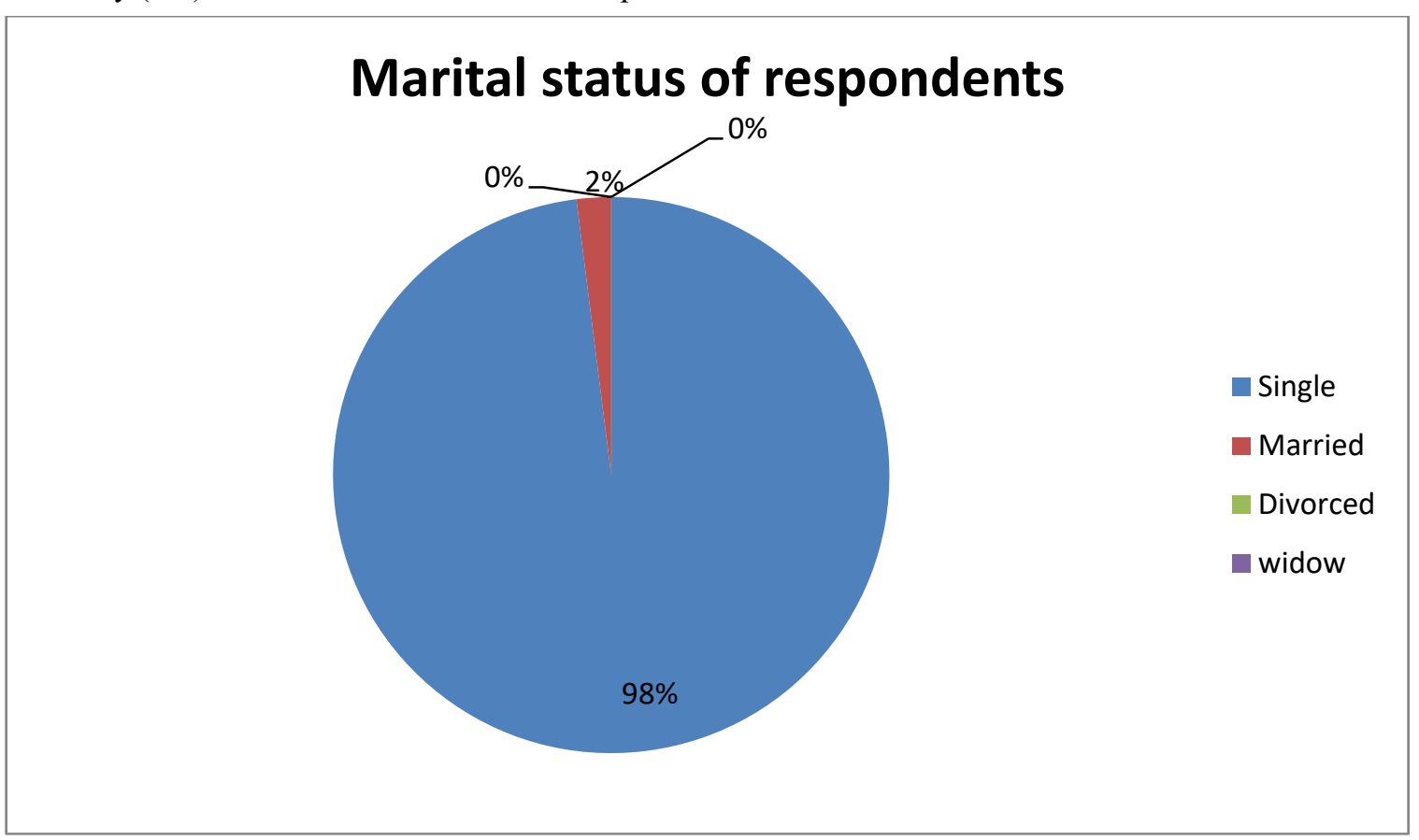

Figure 3. Marital status of respondents in percentages $(\mathrm{N}=295)$

\subsubsection{Gravidity and Parity}

The respondents were asked to indicate their gravidity and parity. Of the 295 respondents, $58.6 \%$ were $\mathrm{G} 0$ and they were the most severely affected by dysmenorrhea, $26.1 \%$ were $\mathrm{G} 1,12.9 \%$ were $\mathrm{G} 2,1.4 \%$ were $\mathrm{G} 3$ and $1 \%$ were $\mathrm{G} 4$. In addition, $60 \%$ were $\mathrm{P} 0$ and were the most severely affected by dysmenorrhea, $25.8 \%$ were P $1,12.5 \%$ 
were P $2,1.7 \%$ were $\mathrm{P} 3$ and $0 \%$ were $\mathrm{P} 4$. The research findings indicated that, in the main, dysmenorrhea affected the non-gravidity and non-parity respondents.

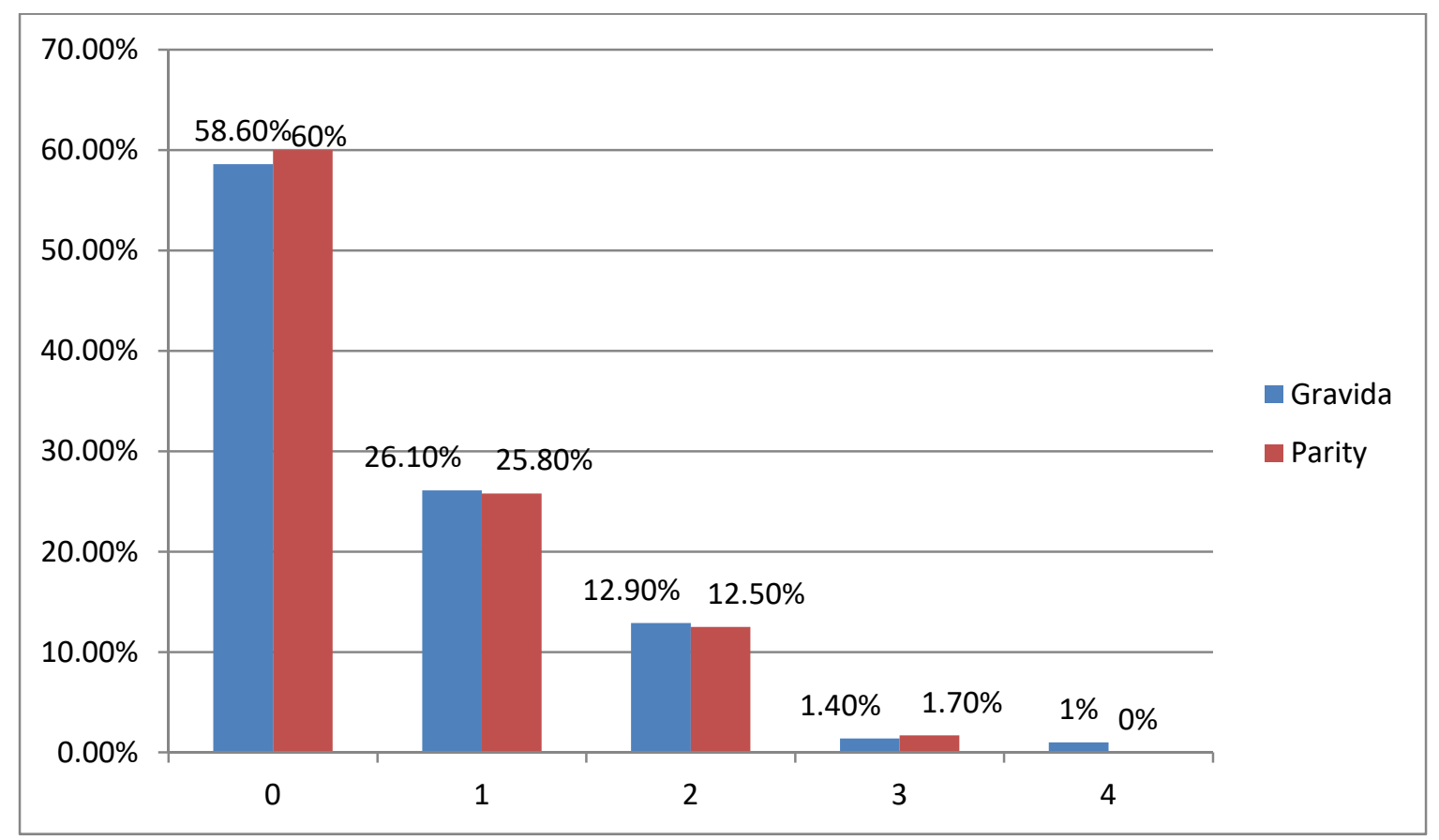

Figure 4. Gravidity and parity of respondents in percentages $(\mathrm{N}=295)$

\section{SECTION B}

\subsection{Knowledge of Students on Dysmenorrhea}

The respondents' knowledge of dysmenorrhea was accessed via variables and the overall knowledge of the respondents determined. The respondents were asked to determine whether the variables were true, false or they were not sure and the participants respond were categorised into level of knowledge in relation to whether their knowledge was adequate or poor. Figure 4.5a indicates the overall knowledge of the respondents in the sense of whether their knowledge was adequate or poor while Figure $4.5 \mathrm{~b}$ indicates the overall knowledge of the respondents per variable. 


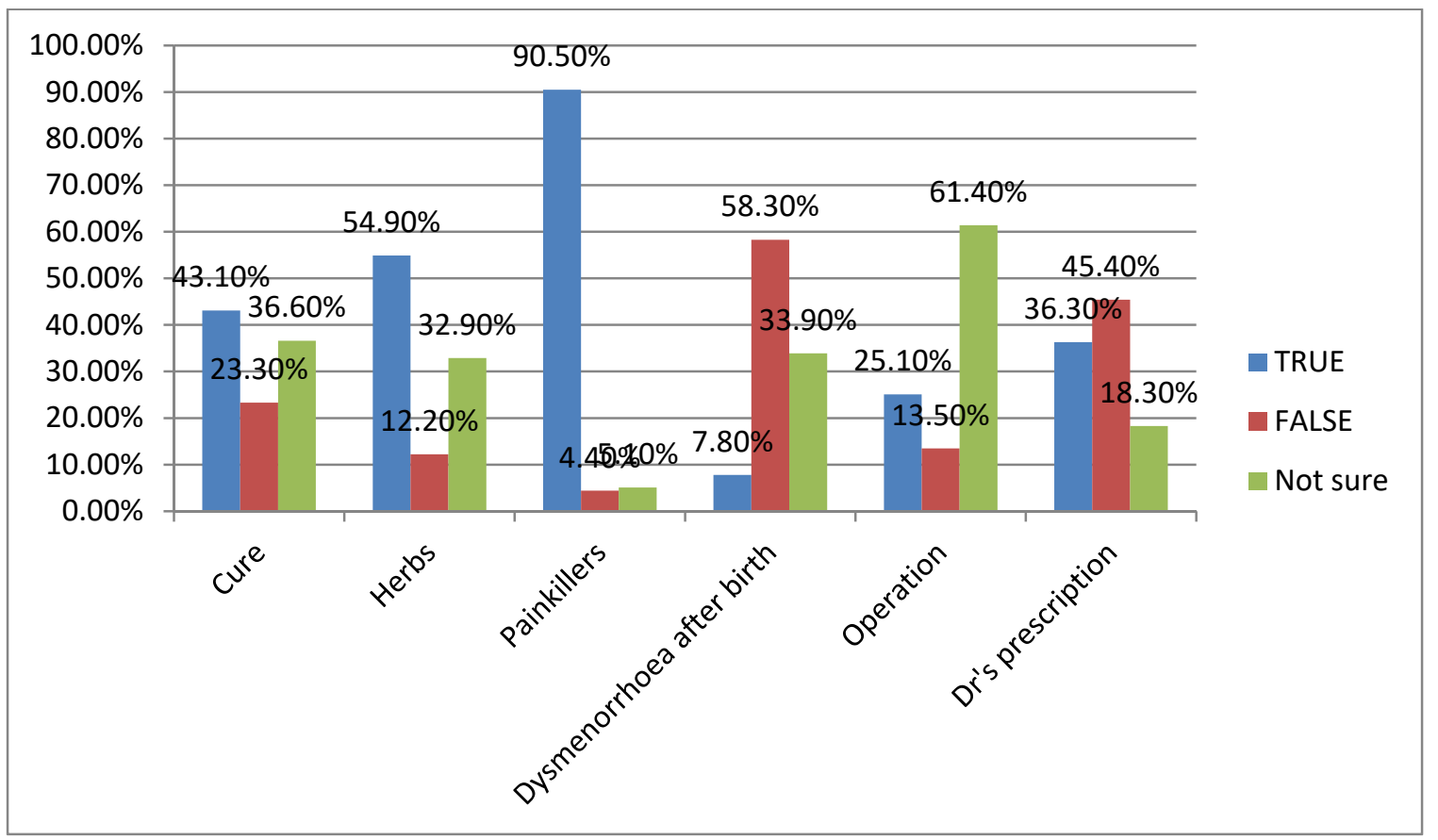

Figure 5a. Responses of the respondents to all the variables

The study found that, overall, the respondents revealed a lack of knowledge on dysmenorrhea as $46 \%$ only appeared to possess adequate knowledge while $54 \%$ had poor knowledge.

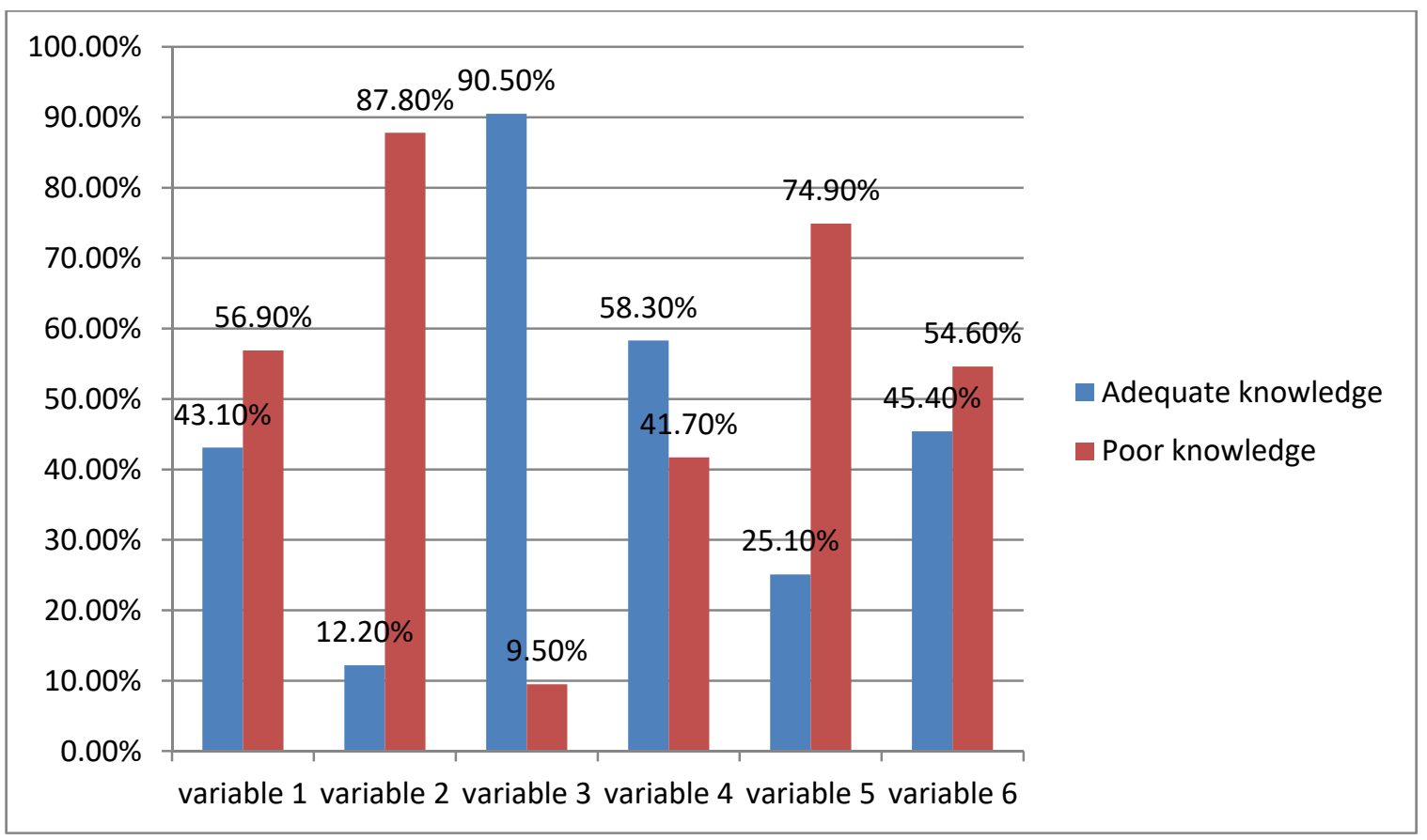

Figure 5 b. Knowledge of respondents on different variables in percentages $(\mathrm{N}=295)$

\section{SECTION C}

\subsection{Practice of Students Regarding the Management of Dysmenorrhea}

\subsubsection{Dysmenorrhic Status}

The researcher wished to ascertain the dysmenorrhic status of the respondents in order to determine which 
respondents were suffering from dysmenorrhea and also their knowledge and practice in respect of dysmenorrhea. Of the 295 respondents, the majority of the respondents $(88.1 \%)$ were experiencing dysmenorrhea with the minority (11.1\%) not experiencing dysmenorrhea. Hence, the latter $11.1 \%$ of the participants were not part of section $\mathrm{C}$ and, thus, 260 respondents only were represented in Section c.

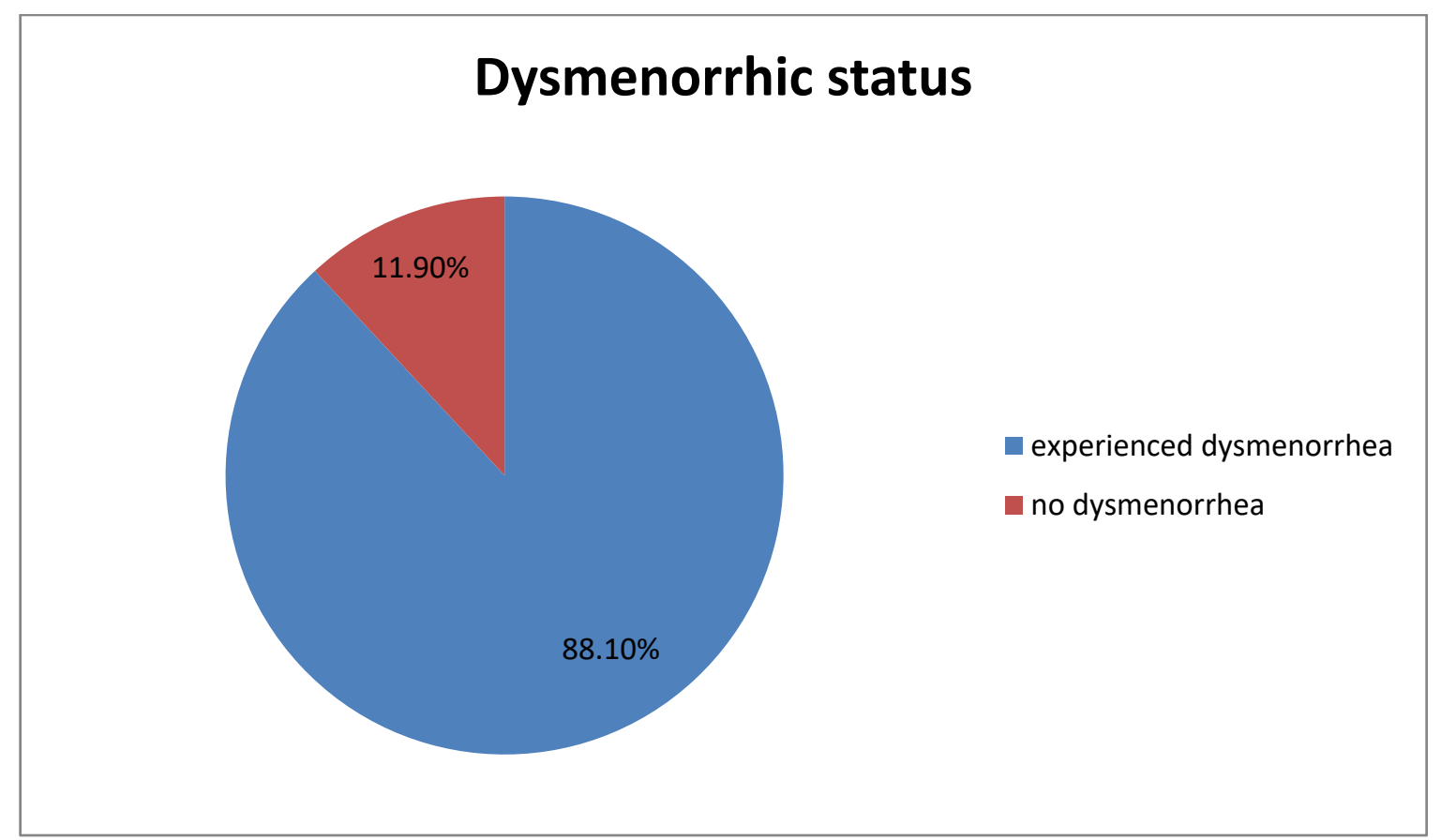

Figure 6. Dysmenorrhic status of respondents in percentages $(\mathrm{N}=295)$

\subsubsection{Use of Traditional Herbs}

The study found that $12.3 \%$ used and $87.7 \%$ did not use traditional herbs. Of the $12.3 \%$ using traditional herbs $90.6 \%$ had found them to be effective while $9.4 \%$ had not found them to be effective.

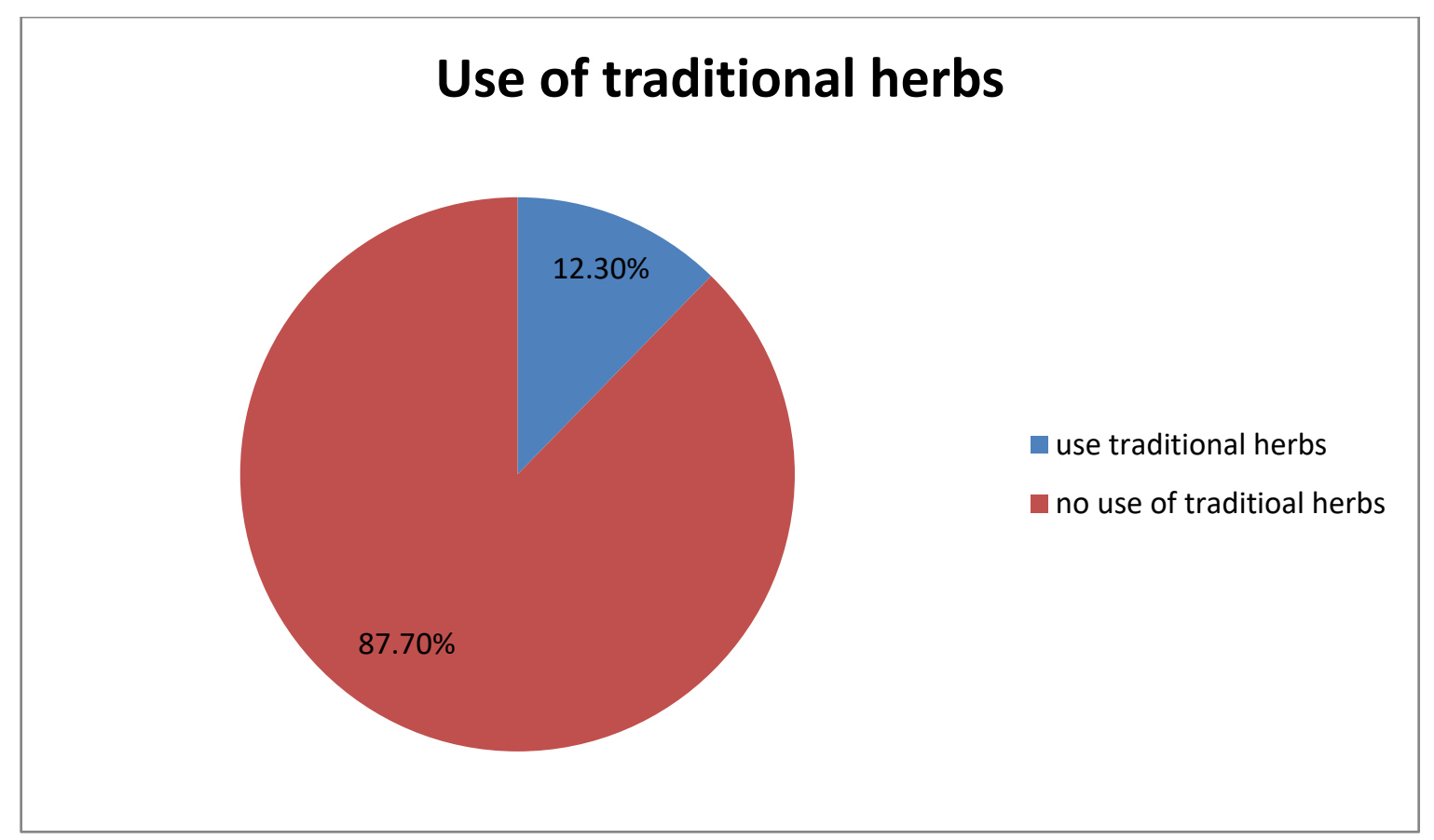

Figure 7. The use of traditional herbs in percentages $(\mathrm{N}=260)$ 


\subsubsection{Seeking Medical Assistance}

The respondents were asked whether they sought medical help when they experienced dysmenorrhea. It emerged that $54.2 \%$ did seek medical help while $45.8 \%$ did not do so. The majority of the respondents (104) who had sought medical help had been given paracetamol, but 76 only had found the paracetamol to be effective while 28 had not found it effective. Dichlophenac had been given to 16 respondents 15 finding it effective and one not finding it effective. Approximately 15 of the respondents had been on other medicine which eight had found them to be effective although seven had not found it effective. In addition, 14 respondents had been given birth control pill which 10 had found to be effective while four had not found them effective.

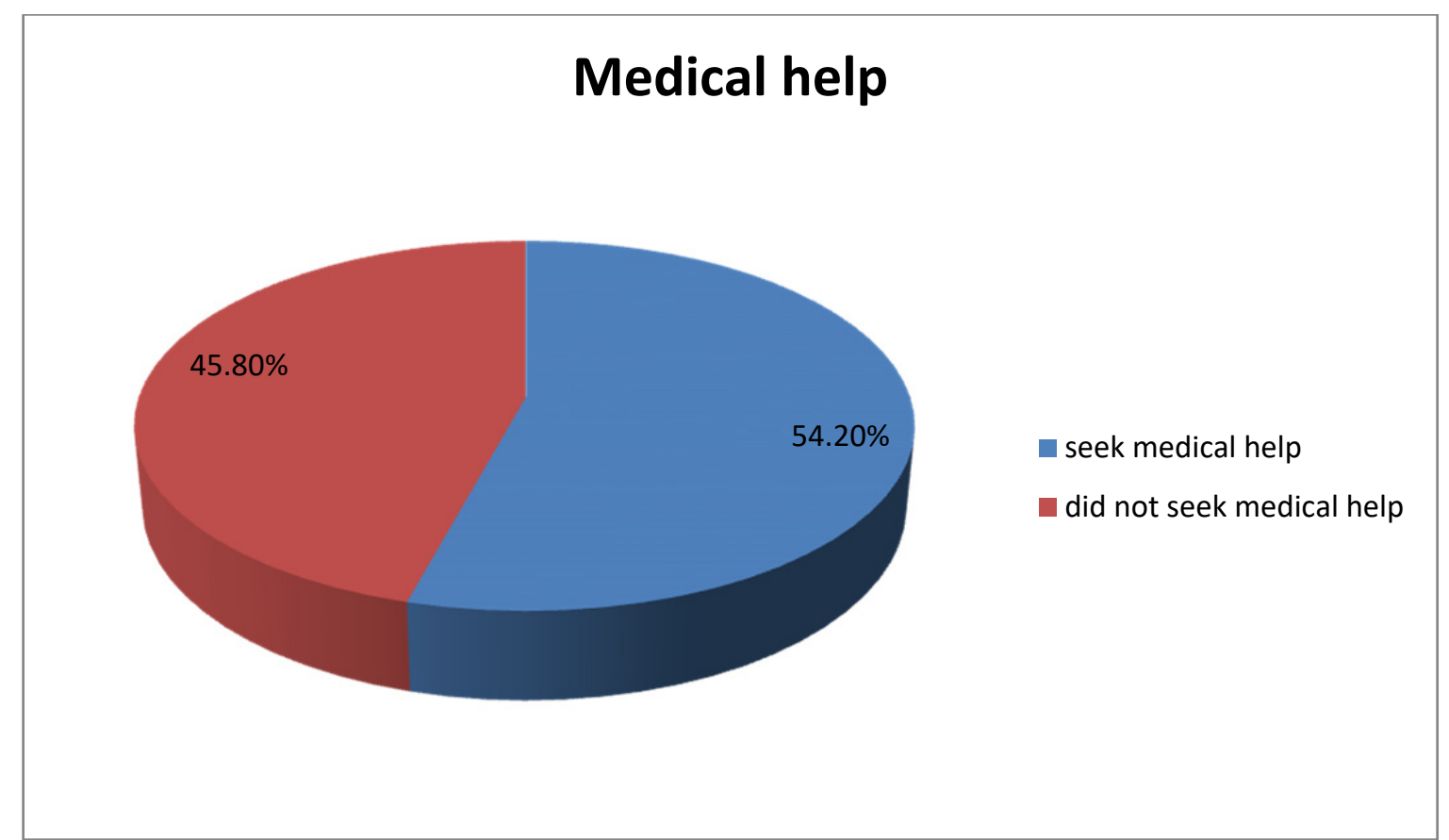

Figure 8. Respondents who sought medical help and those who did not seek medical help in percentages $(\mathrm{N}=260)$

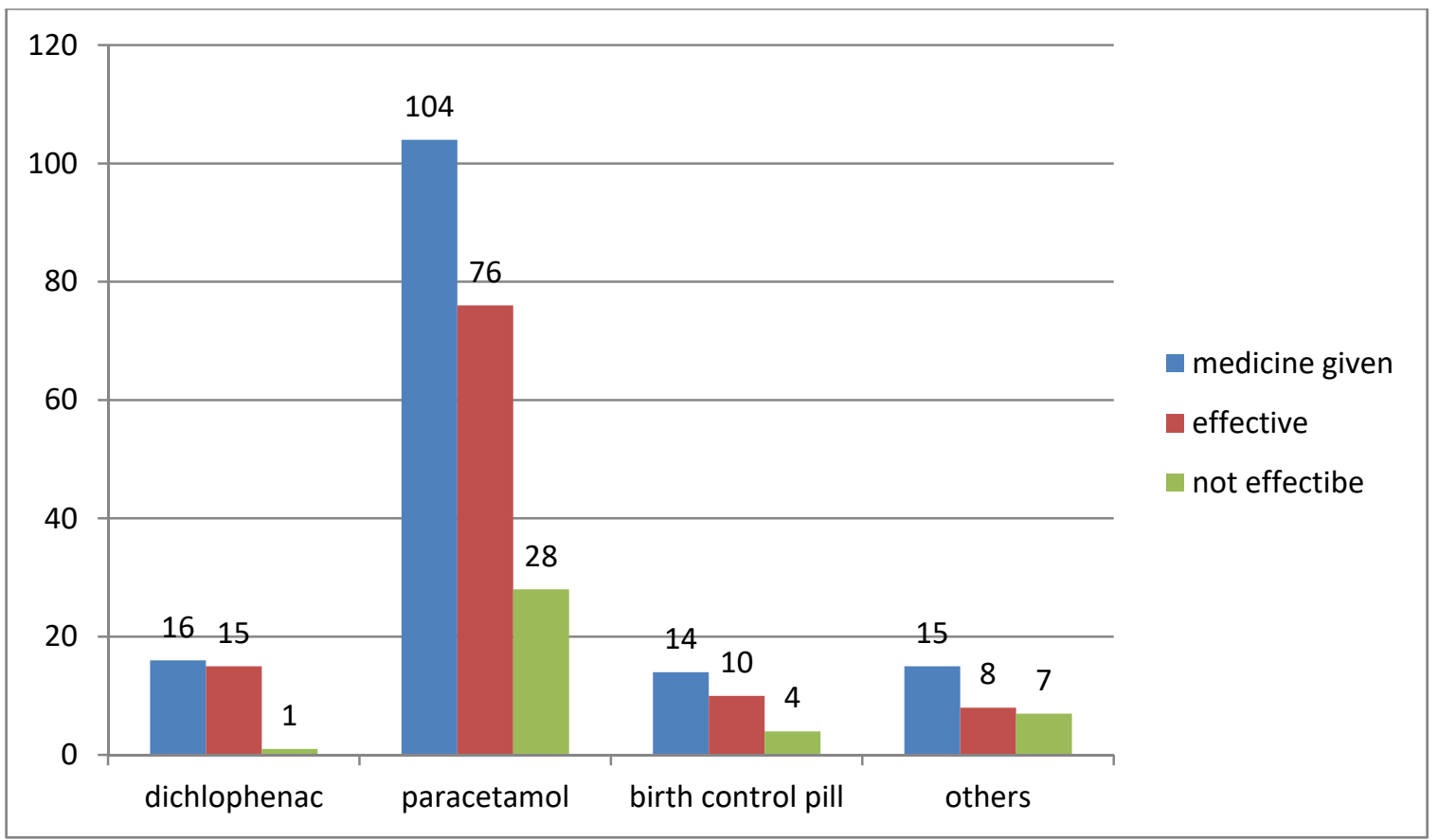

Figure 9. Medicine given to respondents and effectiveness in frequencies $(\mathrm{N}=149)$ 
Table 1. What the respondents did when experiencing dysmenorrhea in frequencies $(\mathrm{N}=295)$

\begin{tabular}{lll}
\hline What the participants did when experiencing dysmenorrhea & Number & Percentages \\
\hline Try different sitting/lying positions & 100 & 34 \\
Use different techniques such as warm baths/massage with warm cloth & 50 & 17 \\
Exercise & 23 & 8 \\
Spend whole day in bed/sleeping & 100 & 34 \\
Drink more water/warm water & 21 & 7 \\
TOTAL & 295 & 100 \\
\hline
\end{tabular}

\section{Discussion of Research Findings}

\subsection{Section A: Demographic Data}

Dysmenorrhea is one of the common conditions affecting young females. The study found that the 22-29 years age group was the most severely affected age group (47.8\%) followed by the 16-21 age group (42\%). In the $22-29$ age group hormonal balance is a problem. Hormone imbalance is one of the most leading causes of dysmenorrhea. Of the total study population $94 \%$ were Christian. The majority of the participants (98\%) were still single because they were young and still completing their studies at university. Finally, nullipara are also the most severely by dysmenorrhea $(58.6 \%)$ as compared to the multigravida.

In addition, in many African cultures menstruation is considered as private and it is believed that painful menstruation is normal. Among the 295 respondents the overall prevalence of dysmenorrhea among female students on the University of Namibia, Rundu Campus was found to be $88.1 \%$ which is comparable to the $83.6 \%$ recorded about university students in Northern Ghana (Ameade, Amalba, \& Mohammed, 2018). Other studies have included $78.1 \%$ of female students at a private university in Ogun State Nigeria who suffered from dysmenorrhoea (Farotimi, Esike, Nwozichi, Ojediran, \& Ojewole, 2017). These varying rates of dysmenorrhea around the world may be attributed to the lack of a universally accepted definition of dysmenorrhea as well as cultural and other factors.

\subsection{Section B: Knowledge of Students of Dysmenorrhea}

The study found that, in the main, the respondents did not have adequate knowledge about the management of dysmenorrhea with $46 \%$ only demonstrating an adequate knowledge of the management of dysmenorrhea and $54 \%$ not having adequate knowledge. This finding may be compared to a study conducted at a private university in Ogun State, Nigeria which also revealed that a less than average of $40.6 \%$ of the participants had a high level of knowledge of dysmenorrhea (Farotimi et al., 2017), thus highlighting that it would appear that the majority of female students suffer as a result of dysmenorrhea which, in turn, affects their daily activities as they do not acquire sufficient knowledge on the success management of dysmenorrhea.

This study found that $43.1 \%$ only of the participants has sufficient knowledge on whether painful menstruation may be cured with 127 out of the 295 respondents demonstrating an awareness of the fact that menstruation pain may be cured. However, there was also a lack of knowledge on the part of some of the respondents as the majority of them did not even know whether there are certain operations that may be performed to treat dysmenorrhea resulting from underlying causes such as a mass in the womb. Such a mass, fibroids or other problems in the uterine wall or within the uterus this may lead to painful menstruation. Thus, if such a mass or the fibroids are removed the dysmenorrhea will be eliminated. According to Chen et al. (2016), a laparoscopy may be used for examination purposes to rule out the causes of dysmenorrhea while a hysterectomy may offer permanent relief for women with dysmenorrhea. This assertion is supported by Calis (2016) who maintain that hormonal treatment, oral contraceptives, combined with surgical treatment, such as an hysterectomy, may be used to eliminate dysmenorrhea completely.

It emerged from the study that very few of the respondents (12.2\%) had any knowledge as to whether it is possible to use home remedies or traditional herbs to treat dysmenorrhea with 36 of the 295 respondents being aware that, although that traditional herbs cannot be used to treat dysmenorrhea they may, nevertheless, be used to relieve the pain caused by dysmenorrhea. De Sanctis et al. (2015) found that that $20 \%$ of the respondents in Hispanic used tea such as green, ginger, raspberry tea and $7 \%$ used herbs to reduce the severity of pain and duration of cramps. Approximately $90.5 \%$ of the respondents in this study (267 of the 295) were aware that painkillers may be used to relieve menstruation pain. In line with this finding Yang et al. (2017) indicated that the majority of students (53\%) 
were using ibuprofen and paracetamol (51\%), which are both painkillers.

Most of the respondent (58.3\%) in this study demonstrated adequate knowledge in management of dysmenorrhoea, since they knew that, even if a woman falls pregnant, the woman may still suffer from dysmenorrhea which is caused by the development of a mass, fibroids or damage to the uterine wall.

Furthermore, $54.6 \%$ of the respondents were clearly not aware that it is possible to buy self-medication to cure dysmenorrhoea, thus indicating $45.5 \%$ only used self-medication. This finding may be compared to the findings that $50-58 \%$ of adolescent undergraduate students in Turkey and Britain, $43.8 \%$ in China, $52-58 \%$ of high school students in the USA and Australia and 33-38\% of young Swedish women use self-treatment for dysmenorrhea (Yang et al., 2017). In addition, Sadiq and Salih (2013) also indicated that 54\% used analgesics without prescription.

\subsection{Section C: Practice of Students Regarding the Management of Dysmenorrhoea}

The study revealed that the minority of the respondents used home remedies. This finding is comparable to the finding of a study conducted among Hispanic female adolescences which revealed that $26.1 \%$ used two to three home remedies (De Sanctis et al., 2015). In the modern world most people do not believe in home remedies while some have no knowledge about home remedies. The study conducted by Gebeyehu et al. (2017) indicated that $63.8 \%$ of the respondents used home remedies as their primary management of dysmenorrhea. This statistic is highly compared to the finding of this study.

However, this study also indicated that more than half of the participants sought medical help when experiencing period pain which is a marked difference to the $25.9 \%$ who consulted a physician in the study conducted by Ortiz (2010), the $16.3 \%$ of students from the Northern University of Ghana who reported seeking help from a hospital for their dysmenorrhea (Ozerdogan et al.,2009) and the 16.2\% of the participants at the University of Gondar in Ethiopia who consulted health professionals about their pain (Gebeyehu et al., 2017). This study revealed that almost half of female students at the University of Namibia, Rundu campus demonstrated have health-seeking behaviours (Dengeinge, Uusiku, Tuhadeleni \& Lifalaza, 2018). However, seeking medical help may be problematic if the individual has no money to pay the taxi fare or hospital bills, long distances to the health facilities and/or traditional beliefs that dysmenorrhea is natural or normal to women. In addition, some women are also shy about talking about or revealing that they are menstruating.

The study also found that the majority of the respondents has been given paracetamol when seeking for medical help, others were given Diclophenac, some did not know which medications they had been given while some had been given birth control pill. In comparison, university students in Northern Ghana cited paracetamol as the most frequently prescribed medication (Ameade et al., 2018), 45.8\% of adolescents in Italy reported allopathic medication as the medication which was prescribed the most frequently with paracetamol being the most commonly used medication (38.1\%) of all types followed by diclofenac (18.6\%) (De Sanctis et al., 2015). In addition, simple analgesics were found to the most common medications used by Hispanic adolescents (53\%) (Kumar et al., 2016). Studies have also indicated that it has been scientifically proven that birth control pills and painkillers may relieve menstruation pain (Kumar et al., 2016).

Some of the respondents in this study tried different sitting/lying positions (34\%), taking a warm bath (17\%), exercising (8\%) and drinking warm water (7\%). However, when all other remedies failed, some of the students reported that they preferred to stay in bed for the whole day (34\%). Similar findings emerged from a study conducted in Italy on dysmenorrhea which found that approximately $72.9 \%$ of the students used various techniques to relieve dysmenorrhoea, including bed rest, while $86.2 \%$ of the students also used self-prescribed medication (Chen et al., 2016).

\section{Conclusion}

The findings of this study revealed that dysmenorrhea was affecting the majority of the female students at the University of Namibia, Rundu campus, especially those between the ages of 16 and 30 years. In addition, it appeared that most of the students lacked knowledge on the management of dysmenorrhea. This may result in poor academic performance on their part as they may be unable to study and perform their daily activities due to their dysmenorrhoea. Approximately 54.2 percent of the students reported seeking medical help, although $45.8 \%$ did not demonstrate health-seeking behaviours. In addition, the study found that a few of the students tried different strategies, using coping mechanisms such as taking a hot shower, exercising and drinking warm water. Nevertheless, empowering the students with knowledge regarding the management of dysmenorrhea may enhance their knowledge and improve their practice in relation to its management, thus enabling them to manage the condition successfully so that it does not impact adversely on their daily activities and their academic studies. 


\section{Competing Interests Statement}

The authors declare that there are no competing or potential conflicts of interest.

\section{References}

Akinnubi, C. A. (2016). Influence of dysmenorrhea and menorrhagia on academic performance of female students in tertiary institutions in Ondo State Nigeria: A literature review. World Journal of Social Science, 3(2), 1-8. https://doi.org/10.5430/wjss. v3n2p34

Ameade, E. P. K., Amalba, A., \& Mohammed, B .S. (2018). Prevalence of dysmenorrhea among University students in Northern Ghana: Its impact and management strategies. Ghana: PubMed.

Antao, V., Black, A., Burnett, M.,Feldmam, K., \& Rorbert, M. (2005). Primary dysmenorrhea consensus guideline. British, London.

Brink, H., Van der Walt, C., \& Rensburg, G. (2015). Foundation of research methodology for healthcare professionals. Cape Town: Juta.

Calis, K. A. (2016), Dysmenorrhea treatment and management. MedScape. Retrieved from https:/www.emedicine.medscape.com/article/253812-treatment\#dr

Chen, X. C., Kwekkeboom, K. L., \& Ward, S. E. (2016). Beliefs about dysmenorrhea and their relationship to self-management: A literature review. Research in Nursing \& Health, 39(4), $263-279$. https://doi.org/101002/nur.21726

Derseh, B. T., Afessa, N., Temesgen, M., Semayar, Y. W., Kassaye, M., Seiru, S., .. Ketsela, K. (2017). Prevalence of dysmenorrhea and it is effect on school performance: A literature review. Journal of Women Health Care, 6(12), 1-6. https://doi.org/10.4172/2167-0420.1000361

De Sanctis, V., Soliman, A., Bernasconi, S., Bianchin, L., Bona, G., Sanctis, M. D., ... Perissinotto, E. (2005). Primary dysmenorrhea in adolescents: Prevalence, impact and recent knowledge. Italy: PubMed.

Farotimi, A. A., Esike, J., Nwozichi, C. U., Ojediran, T. D., \& Ojewole, F. (2017). Knowledge, attitude and healthcare seeking-behavior towards dysmenorrhea among female students at a private school in Ogun State. Journal of Basic and Clinical Reproductive Sciences, 1-7. Retrieved from https://www.jbcrs.org

Gray. D. E. (2014). Doing research in the real world. California: Sage Publications.

Gebeyehu, M. B., Mekuria, A. B., Tefera, Y. G., Andarge, D. A., Debay, Y. B., Bejiga, G. S., \& Gebresillassie, B. M. (2017). Prevalence, impact, and management practice of dysmenorrhea among University of Gondar students, Northwestern Ethiopia: A literature review. International Journal of Reproductive Medicine, 1-8. https://doi.org/ 10.1155/2017/3208276

Hornby, A. S. (2010). Oxford advanced learner's dictionary of current English. New York: Oxford University Press.

Kumar, R. (2014). Research methodology: A step by step guide for beginners. Los Angeles, CA: Sage Publications.

Kumar, K. S., Konjengbam, S., \& Devi, H. S. (2016). Dysmenorrhea among higher secondary schoolgirls of Imhpal, West District, Manipur: A literature review. Journal of Medical Society, 30(1), 1-6. Retrieved from https://www.jmedcoc.org

Kural, M., Noor, N. N., Pandit, D., Joshi, T., \& Patil, A. (2015). Menstrual characteristics and prevalence of dysmenorrhea in college going girls: A literature review. Journal of Family Medicine and Primary Care, 4(3), 1-4. https://doi.org/10.4103/2249-4863.161345

Ortiz, M. I. (2010). Primary dysmenorrhea among Mexican university students: Prevalence, impact and treatment. Mexico, PubMed.

Ozerdogan, N., Sayiner, D., Ayranci, U., Unsal, A., \&Giray, A. (2009).Prevalence and prediction of dysmenorrhea among students at University in Turkey. International Journal of Gynaecology and Obstetrics.

PubMed Health. (2016). Period pain: overview. Retrieved from https://www.ncbi.nlm.nih.gov/pubmedhealth

Sadiq, M. A., \& Salih. A. A. (2013). Knowledge and practice of adolescent females about menstruation in Bagdad: A literature review. Journal of General Practice, 2(1), 1-4. https://doi.org/10.4103/2249-4863.161345

Sinha, S., Srivastava, J. P., Sachan, B., \& Singh, R. B. (2016). A study on menstrual pattern and prevalence of dysmenorrhea during menstruation among school going adolescents girls in Lucknow District, Uttar Pradesh, 
India: A literature review. International Journal of Community Medicine and Public Health, 3(5), 1-4. https://doi.org/10.8203/2394-6040.ijcmph20161384

Welman, J. C., Kruger, F., \& Mitchell, B. (2011). Research methodology. Cape Town: Juta.

Yang, M., Chen, X., Bo, L., Lao, L., Chen, J., Yu, S., ... Liang, F. (2017). Moxibushon for pain relief in patients with primary dysmenorrhea: A randomized controlled trial: A literature review. PLoSONE, 12(2). https://doi.org/10.1371/journal.pone,0170982

\section{Copyrights}

Copyright for this article is retained by the author(s), with first publication rights granted to the journal.

This is an open-access article distributed under the terms and conditions of the Creative Commons Attribution license (http://creativecommons.org/licenses/by/4.0/). 